\title{
UTILIZAÇÃO DA FIBRA DE RÁFIA COMO ADIÇÃO EM SOLO-CIMENTO PARA PRODUÇÃO DE TIJOLOS ECOLÓGICOS: UMA AVALIAÇÃO FÍSICO-MECÂNICA
}

\author{
Ádila Michele Santos ${ }^{1}$ \\ Marina Gomes Passos ${ }^{2}$ \\ José Humberto Teixeira Santos ${ }^{3}$ \\ Fernanda Nepomuceno Costa ${ }^{4}$
}

Resumo: À medida que a construção civil impacta negativamente o meio ambiente, buscam-se cada vez mais soluções que viabilizem a relação desenvolvimento-sustentabilidade. Visando encontrar o material e proporção ideais para produzir solo-cimento acrescido de resíduo que seja estável, resistente e durável, diversos materiais têm sido utilizados em estudos no comportamento técnico e mecânico do composto solocimento. O presente trabalho baseia-se na análise do desempenho do solo-cimento incorporado com fibra de ráfia, proveniente de sacarias residuais do município de Cruz das Almas - BA. Os resultados obtidos dos ensaios de resistência à compressão axial e absorção de água por imersão, indicaram que com o aumento da quantidade de fibra, a resistência mecânica evoluiu até certo ponto, a partir do qual, voltou a reduzir, e com o aumento da proporção de resíduo, houve redução da absorção de água em razão de ter-se elevado a impermeabilidade do composto.

Palavras-chave: Construção; Solo-cimento; Fibra de ráfia; Sustentabilidade.

\footnotetext{
1 Graduanda em Engenharia Civil, Universidade Federal do Recôncavo da Bahia, Brasil. E-mail: adila_micheli@hotmail.com.

2 Graduanda em Engenharia Civil, Universidade Federal do Recôncavo da Bahia, Brasil. E-mail: marygpassos@hotmail.com.

3 Professor Adjunto I, Universidade Federal do Recôncavo da Bahia, Brasil. E-mail: jhtsantos@yahoo.com.br.

${ }^{4}$ Professora Assistente, Universidade Federal do Recôncavo da Bahia, Brasil, fernandacosta@ufrb.edu.br.
} 